\title{
Longitudinal effects of social background on educational and occupational pathways within early and strong school tracking
}

Robin Samuel - Visiting Scholar, Center on Poverty and Inequality, Stanford University; Visiting Scholar, Department of Sociology, University of Cambridge; Department of Social Sciences, University of Basel robin.samuel@unibas.ch

Manfred Max Bergman - Department of Social Sciences, University of Basel; Centre of Research on Evaluation, Science and Technology, Stellenbosch University

Sandra Hupka-Brunner - Department of Social Sciences, University of Basel

(Received June 2013 Revised December 2013)

DOI: http://dx.doi.org/10.14301/llcs.v5i1.258

\section{Abstract}

Transitions from education to work are subject to person-related factors and institutional opportunity structures. Life course research increasingly focuses on longitudinal effects of social background on educational and occupational pathways within early and strong school tracking. In this context, Switzerland is a paradoxical case because its education system exhibits elements that should both reinforce and weaken social background effects. We draw on data from a PISA 2000 school-leaver cohort. Employing sequence analysis, optimal matching and longitudinal latent class analysis, we find that persistence tendencies are more pronounced in the academic stratum, compared to vocational and precarious strata. Conversely, the education system and labour market allow for a good integration of weak academic performers. Overall, we show that social background and performance determine selection into tracks, after which effects of opportunity structures take over.

Keywords: transition, tracking, social background, pathways, labour market entry

\section{Introduction}

Transitions from education to work and employment depend on person-related factors and institutional opportunity structures. Opportunity structures entail the interplay between the education system, labour market, employment policies, legal arrangements and socio-cultural norms. They determine the framework for educational and occupational pathways (Blossfeld \& Maurice, 2011; Schoon \& Silbereisen, 2009). Education systems differ by focus, type and degree. Some are characterised by weak tracking, late selection, high tertiary education quota and an emphasis on general education (e.g. UK, USA and Canada). Others feature early selection and specialization, a strong tradition of apprenticeships and low tertiary education quota (e.g. Germany, Denmark and Austria). Comparative transition research assumes that characteristics of education systems affect post-compulsory educational and occupational pathways in different ways. For example, Bauer and Riphahn (2006) found that strong tracking at the secondary level I increases the effect of social background on educational and occupational achievement. Gangl (2001) showed that education systems with a focus on vocational training at the secondary level II facilitate labour market entry.

In this regard, the Swiss education system is an interesting case. First, it features early and strong tracking at secondary level I. Second, the Swiss education system is characterized by a low tertiary 
quota and dual vocational training (VET), in which learners attend a vocational school for up to two days per week. For the rest of the week they work in a host company. Third, the secondary level II structure facilitates the integration of academically weak young people and provides prospects for a smooth transition into the labour market, as corroborated by a low youth unemployment rate. Hence, Switzerland serves as a paradoxical case study because its education system exhibits elements that should reinforce and weaken social background effects.

In this paper, we examine the effects of social background on educational and occupational pathways in Switzerland with a particular focus on tracking and transitions. To achieve this, we first provide an overview of the state of international research and propose a theoretical framework. Given the focus on longitudinal processes in this paper, we draw on life course theories (Baltes, 1987; Elder, 1994; Kohli, 2007; Levy, Ghisletta, Goff, Spini, \& Widmer, 2005), which allow a dynamic understanding of the multi-faceted effects of social background. We then describe the post-compulsory pathways of a school-leaver cohort, using sequence analysis and optimal matching and finally test hypotheses employing longitudinal latent class analysis.

\section{State of research and theoretical framework}

The influence of social background on educational and occupational pathways has been well-covered in the research literature. In a recent longitudinal multi-cohort study in Sweden, for example, Goodman and colleagues (2010) find that family socio-economic status not only predicts school achievement in elementary school but also attendance of secondary school, as well as entry into tertiary education. Apparently, social background matters at different transitions, and there is evidence for cumulative effects. These findings corroborate earlier research in Sweden (Erikson \& Jonsson, 1996) and twelve other countries (Blossfeld \& Shavit, 1993). For the UK, Gregg and Macmillan (2010) analyse the effect of familial economic background on the offspring's educational outcome in five cohorts. The authors provide evidence for equalising educational differences across family background for children aged 10, 11 and 16, although it is unclear how these children will fare in terms of labour market returns (Mclntosh, 2006). Finnie and Mueller (2009) come to a similar conclusion, using data from the Canadian Youth in Transition Survey. In this study, the PISA reading ability scores appear to be a strong predictor of academic participation. Using the same data, Bowlby and McMullen (2002) find that the level of parents' education was positively associated with completing high school. Furthermore, dropouts and leavers seem to suffer from stigmatisation and were facing various barriers in obtaining the education they aspired to. For Norway, Andersen and Hansen (2012) show that cultural resources are positively associated with school performance across a variety of educational fields and effects within educational tracks. Based on the Longitudinal Surveys of Australian Youth and Youth in Focus data, Homel and colleagues (2012) find some evidence for an overestimation of commonly used indicators of social background, such as parental education and occupation, on educational success. For example, comparably undesirable educational outcomes of young people from disadvantaged backgrounds seem to result from "the negative experience of schooling" they are more likely to undergo. More recent research aims at disentangling the effects of performance and choice (Bukodi \& Goldthorpe, 2013; Jackson, 2013; Schindler \& Lörz, 2012), which is especially fruitful in choice-driven education systems, such as England and Sweden (Jackson, Jonsson, \& Rudolphi, 2012). This overview shows that personal and social resources affect educational and early occupational pathways in many countries. Most likely, institutional opportunity structures - as the interplay between the education system, labour market, employment policies, legal arrangements and socio-cultural norms - affect how resources are transformed into educational and occupational outcomes.

Germany and Switzerland are examples of countries that feature early selection and specialization, VET and low tertiary education quota. Research from Germany suggests that the effect of social background is mediated by educational pathways. Indirect effects of social background seem to increase at each transition within the education system (Berger \& Kahlert, 2005). Direct social background effects, in contrast, diminish over time (Becker, 2010). The influence of social background seems particularly strong for unconventional educational pathways (Konietzka, 2010). For these, the effect of social background is 
predominantly indirect, particularly when different educational sequences are strongly linked. It is not clear whether these findings also pertain to Switzerland, which shares many features with the German education system. However, there are many important differences that go unnoticed in the current research debate. German learners work towards a school certificate at secondary level I, which subsequently influences their prospects in the labour market. Consequently, it is an attractive yet risky strategy to stay at school to obtain a higher certificate. In Switzerland, there are no certificates at secondary level I.

At secondary level II, Germany's labour market is characterised by big companies, while in Switzerland, Small and Medium Enterprises (SMEs) predominate. As a result, selection criteria are less standardised in Switzerland. This is considered to be less meritocratic but might also benefit academic weak performers in some instances (Buchholz, Imdorf, Hupka-Brunner, \& Blossfeld, 2012). Furthermore, it is common for young people in Germany to enter a VET programme after passing the Abitur (A-levels, Matur etc.), which is rare in Switzerland.

These are just a few of the differences between two countries that have a similar educational system. Consequently, we believe that the Swiss case warrants separate analysis. This will provide important information for countries without a VET system, but will also offer others with VET systems the possibility to learn about how specific opportunity structures affect the transfer of social advantages.

Research in Switzerland reveals strong effects of social background on academic performance and participation in education (Bauer \& Riphahn, 2006; Becker \& Hecken, 2009a, 2009b; Coradi Vellacott, Hollenweger, Nicolet, \& Wolter, 2003; Joye, Bergman, \& Lambert, 2003). Moreover, tracks with extended intellectual requirements are particularly selective (Zutavern, Brühwiler, \& Biedermann, 2002). Familial cultural resources seem to be most important for acquiring reading skills (Coradi Vellacott et al., 2003; Jungbauer-Gans, 2004; Kronig, 2007; Moser, 2004; Neuenschwander \& Malti, 2009) and entering post-obligatory education programmes (Hupka-Brunner, Sacchi, \& Stalder, 2010). However, most of the cited studies are based on cross-sectional data and focus on special groups. A comprehensive analysis of when and how social background affects pathways in Switzerland, and to what extent the accumulation and mediation of advantages and disadvantages may be observed has not been conducted to date. This is surprising because, in comparison to other countries, tracking in Switzerland is pronounced and occurs early. In most cantons, the semi-sovereign states within Switzerland, elementary school lasts six years, after which learners are assigned to different tracks at the age of around 12 years ( $6^{\text {th }}$ grade; ISCED-Level 2; SKBF, 2010). The assignment to different tracks is based on grades, and various assessments, as well as parents' and learner's wishes (Neuenschwander, Gerber, Frank, \& Rottermann, 2012).

Only 10 percent of an age cohort is in integrated school types after elementary school, where learners are in the same class regardless of academic performance (BFS, 2007a). After three years, i.e. nine years of compulsory school and an average age of 15 years, learners make the transition from secondary level I to secondary level II ( $9^{\text {th }}$ grade; ISCED 3). Secondary level II is divided into VET tracks (65 percent of the learners) and general education tracks with demanding intellectual requirements (20 percent, Gymnasium ${ }^{1}$ and specialised middle schools; BFS, 2007a). The type of school attended at secondary level I largely determines the type of education selected by learners at secondary level II. This holds especially for higher educational strata. Learners who attended a secondary level I school with basic scholastic performance requirements are unlikely to attend a Gymnasium, just as transitions from Gymnasium to VET tracks are rare in Switzerland.

In Switzerland, VET is highly differentiated and a popular choice. Some training programmes require only basic scholastic performance, while others require competences comparable to academic tracks (Hupka-Brunner et al., 2010; Moser, 2004; Stalder, 2005). Apprentices attend a vocational school up to two days per week, and spend the rest of the week in a host company. Thus, they become part of the workforce at an early stage and are more likely to manage labour market entry more easily. However, some learners postpone vocational training due to a lack of apprenticeship positions, leading to a delayed entry. Changes from one vocational training programme to another are rare and costly. The type of vocational training and the subsequently selected occupation are strongly 
The effects of social background on educational and occupational pathways...

linked, because qualifications are required in most cases.

Gymnasium graduates enter university after obtaining a Matur, typically at the age of 18 or 19 (A-levels, high school diploma; cf. Endnote 1). The Matur allows enrolment in any discipline except in medicine. Only 20 percent of a school-leaver cohort obtain this certificate, 90 percent of which enter university (SKBF, 2010). An alternative path to university exists via the federal vocational baccalaureate. A federal vocational diploma allows entry into tertiary education, i.e. universities of applied sciences (Fachhochschule in Germany and Austria), where an academic degree with a focus on professional skills may be obtained. This increases the permeability of the otherwise rigid Swiss education system and diminishes social background effects. Since the mid-1990s, the proportion holding a federal vocational baccalaureate has increased to about 10 percent (BFS, 2007a). However, only 60 percent of holders of a federal vocational baccalaureate enter a university of applied sciences (BFS, 2007b). Accordingly, labour market entry may occur at various stages. Young people in vocational certificate tracks may enter when they are approximately 18 years of age. Those pursuing an academic track enter employment six years after completing compulsory school at the earliest. The vast majority of young people transfer smoothly into the labour market. Youth unemployment rates are low, averaging 7 percent for the 15 to 24 years olds between 2001 and 2011 (own calculations based on ILO, 2011).

In sum, Switzerland exhibits strong and early tracking. The academic track appears highly selective, while VET is open to low- and highperforming learners with a heterogeneous social background. Accordingly, we expect an accumulation of advantages due to cumulative effects of social background and comparably low tertiary education participation. These effects may be observed as persistence tendencies, i.e. a quantifiable propensity of members of a certain stratum to stay in their stratum over time. The propensity is co-determined by personal and social resources as well as opportunity structures. Changes of education or employment are more common in less selective educational programmes. On this education level, tracks are more permeable. Fluctuations between lower strata may be substantial because the Swiss labour market performs well in integrating people. We thus expect the persistence tendency to be lower for members of less selective strata. In other words, people should be able to move easily between the lower tracks. $^{2}$

Accordingly, we propose the following hypothesis:

1) In early and strong tracking, the persistence tendency is highest in the academic stratum and lower in less selective tracks.

\section{Effects of social background on educational and occupational pathways}

Life course theories have been widely employed to study educational pathways. The positions within pathways may be conceived of as strata (Elder, 1975). Based on Elder's work (1994), contemporary life course research focuses on long-term processes (Blossfeld \& Maurice, 2011). Life courses are always conceived of as "linked lives," entangled with the life courses of significant others, such as parents, partners and peers (Levy et al., 2005). In this vein, we examine how different strata are linked over time. A strong linkage of strata implies accumulation processes of advantages and disadvantages (Elder, 1994; Merton, 1968). Hence, this strand of theorization is connected to social reproduction (Bourdieu, 2000; Bukodi \& Goldthorpe, 2013; Erikson \& Goldthorpe, 1992). From this perspective, different social and personal resources affect pathways at different educational and occupational stages. For example, Maaz, Watermann, \& Baumert (2007) find evidence that the effects of cultural resources are constrained to the transition from compulsory school to secondary level II. In general, Switzerland seems to exhibit comparably weak effects of cultural resources on educational pathways, compared to Austria and Germany (Maaz et al., 2007). Especially reading skills are considered crucial for successful completion of secondary level II (OECD/PISA, 2001). As they often indicate general learning abilities, they should also affect entire pathways (Heinz, Weymann, \& Huinik, 2009; Stalder, Meyer, \& Hupka, 2008).

Our research provides evidence for social reproduction and social closure if, for example, young people with an academic background transfer to academic tracks at secondary level II and subsequently transfer to university. Analogously, young people from a socially disadvantaged 
background are more likely to be found in precarious educational and occupational situations, such as unemployment.

We outlined different transitions in the education system crucial to early employment trajectories. Also, most studies show that the effect of social background at different points in an educational pathway varies, and cumulative effects are likely (e.g. DiPrete \& Eirich, 2006; Mare, 1980). Accordingly, we hypothesize:

2) The direct effect of social background on stratum membership is stronger at entry into secondary level II, than during secondary level II and the transition to the labour market or university. The direct effect of social background on stratum membership decreases across transitions.

\section{Data}

For this article, we use the Swiss youth panel Transitions from Education to Employment, a nationally representative PISA 2000 follow-up study (TREE, 2011). These data are unique in that they allow the observation of educational and occupational pathways across secondary levels I and II, as well as tertiary education and labour market entry. The PISA sample was drawn from the schoolleaver cohort at the end of compulsory schooling in 2000 ( $9^{\text {th }}$ grade) when the majority of the respondents were around 15 years old. A two-stage, multiple disproportionate, random sampling technique was employed, controlling for language regions and the participating cantons (Renaud, Ramseier, \& Zahner, 2000; Sacchi, 2011). The initial sample comprised 6,343 young people from 312 schools. The cohort was surveyed annually from 2001 to 2007. Attrition was addressed using full information maximum likelihood with a robust (MLR) estimator (Raykov, 2005). The data set used for the final model contained 5,117 cases (Appendix 2).

\section{Measures}

We recoded all educational or occupational situations into four strata, so as to allow an analytical examination of social background effects on pathways. We did this at every time point. The academic stratum comprises Gymnasium and tertiary education. In the demanding vocational stratum, we include VET programmes with extended scholastic performance requirements (demanding VET). VET programmes with low to medium requirements, as well as certified employment, are subsumed into the vocational and working stratum (VET or vocational). The precarious stratum includes young people not enrolled in secondary level II education (e.g. unemployed, gap year) or working without a certificate. We chose this strategy because it is not possible to meaningfully apply well-established measures such as the Goldthorpe class schema (Goldthorpe, Llewellyn, \& Payne, 1987; Goldthorpe, 1996). Transitions are complicated as Figure 1 and 2 depict. While some part of the cohort is already integrated in the labour market, others have not yet found an apprenticeship and yet others are still at university. The covered period of seven years does not allow us to observe destinations in terms of occupations for the majority of the sample.

The analyses of the effects of social background on educational and occupational pathways (hypotheses 1 and 2 ) require the inclusion of further scales and indices. We use four indicators measured by PISA at the end of compulsory school (Adams \& Wu, 2002): Familial economic resources are operationally defined by the family's possessions. ${ }^{3}$ Parents' education is measured by the education level of either father or mother (the latter is used when there was no information on the former). Parents' socio-economic status (HISEI) is based on their occupation. Families' cultural resources are proxied by a composite measure that comprises number of books and information on possession of cultural goods (e.g. classic literature, paintings). As reading skills affect entire educational trajectories and indicate general learning abilities (Heinz et al., 2009; Stalder et al., 2008) we describe pathways based on reading skills as measured by PISA (OECD/PISA, 2001). These are also recoded into four strata (refer to Appendix $1 \mathrm{a}$ and $1 \mathrm{~b}$ for all cross-sectional descriptives). ${ }^{4}$

\section{Analytic plan}

Our analysis consists of two steps. To describe educational and occupational pathways, we first employ optimal matching and sequence analysis (Abbott \& Tsay, 2000; Brzinsky-Fay, Kohler, \& Luniak, 2006; Gabadinho, Ritschard, Studer, \& Müller, 2010). Optimal matching clusters pathways according to similarity. Similarity relates to the extent to which trajectories are composed of the same educational and occupational states over time. To show the effects of personal resources on the trajectories, we use reading skills as a starting 
point. The clustered pathways are visualized to allow for a more intuitive interpretation of the results. Subsequently, sequence analysis helps to establish an understanding of variations of typical pathways in the data set, using entropy as a descriptive measure. Entropy provides a summary of the variation in empirical educational and occupational states over time and further enhances the interpretability of the optimal matching results.

Second, we use Latent Transition Analysis (LTA) to study the patterns of movement between strata and across pathways, conditional on social background (Humphreys \& Janson, 2000; Lazarsfeld, 1968; Nylund, 2007; Wiggins, 1973). LTA examines the time-dependency of any given stratum across different thresholds in the education system (Chung, Park, \& Lanza, 2005; Lin, Ten Have, \& Elliott, 2009; Miglioretti, 2003; Muthen \& Muthen, 2000; Reboussin \& lalongo, 2010). Furthermore, it allows estimating the effects of social background on stratum membership across transitions. LTA provides all information necessary to test hypotheses 1 and 2 . Our LTA comprises of an autoregressive structural equation model with a latent class analysis as the model of measurement at every time point. The autoregressive elements prevent biased estimates of covariates as they account for preceding strata. Every stratum is conceived of as one of $k$ latent classes. We use $k-1$ dummy variables, each representing one type of stratum membership at every time point (the reference category is the academic stratum). Upward and downward mobility as well as persistence are quantified in the form of probabilities. These probabilities are estimated as first order transition probabilities,

$P\left(C_{i t}=k \mid C_{i(t-1)}=m\right)=\frac{\exp \left(\alpha_{k}+\beta_{1 k} d_{i 1}+\beta_{2 k} d_{i 2}+\beta_{3 k} d_{i 3}\right)}{\sum_{l=1}^{4} \exp \left(\alpha_{l}+\beta_{11} d_{i 1}+\beta_{2 l} d_{i 2}+\beta_{3 l} d_{i 3}\right)}$,

with $\alpha_{4}=0, \beta_{14}=0, \beta_{24}=0$ and $\beta_{34}=0$ for an LTA with four classes (cf. Nylund, 2007). ${ }^{5}$

The dependency of transitions over time may cause biased standard errors. In our case, the comparably large sample size and the use of MLR standard errors (robust to non-normality and dependent observations; calculated with a sandwich estimator) address this potential problem.

\section{Characteristics of post-compulsory educational and occupational pathways}

Figure 1 depicts the pathways of the PISA 2000 school-leaver cohort. The first column shows the PISA readings skills. The subsequent columns present various educational and occupational outcomes from 2001 to 2007. The last column presents the certificate obtained by 2007.

The pathways diverge over time, and the variation is highest between 2004 and 2006. During this time, the majority of the cohort enters the labour market or tertiary education. Most pathways end in employment or tertiary education.

Young people with high reading competencies seem to be a homogenous group with regard to their pathways. Most make the transition to the Gymnasium (78\% within two years after leaving compulsory schooling). A small proportion enrols in VET with higher scholastic achievement requirements and then enters the labour market, while others enter tertiary education after they obtained a Matur. Only a few with high reading competencies are without educational credentials at secondary level II, one year after completion of compulsory school (6\%). Downward mobility or working without occupation-specific credentials is rare.

Young people with low, medium-low and medium-high reading skills are less frequently found in academic tracks but enrol predominantly in VET. During secondary level II, episodes outside the education system are rare and primarily observed at the beginning and the end of educational programmes. ${ }^{6}$ These gaps follow two main patterns. First, a break occurs between Gymnasium and tertiary education (e.g. gap year overseas, language stay). Second, after VET, breaks appear more frequent and of longer duration. Furthermore, uncertified employment is prevalent when reading skills are low (Figure 1). It is noteworthy that participation in tertiary education following VET with high requirements is rare. 
The effects of social background on educational and occupational pathways...

\section{Figure 1. Optimal Matching visualisation of pathways}

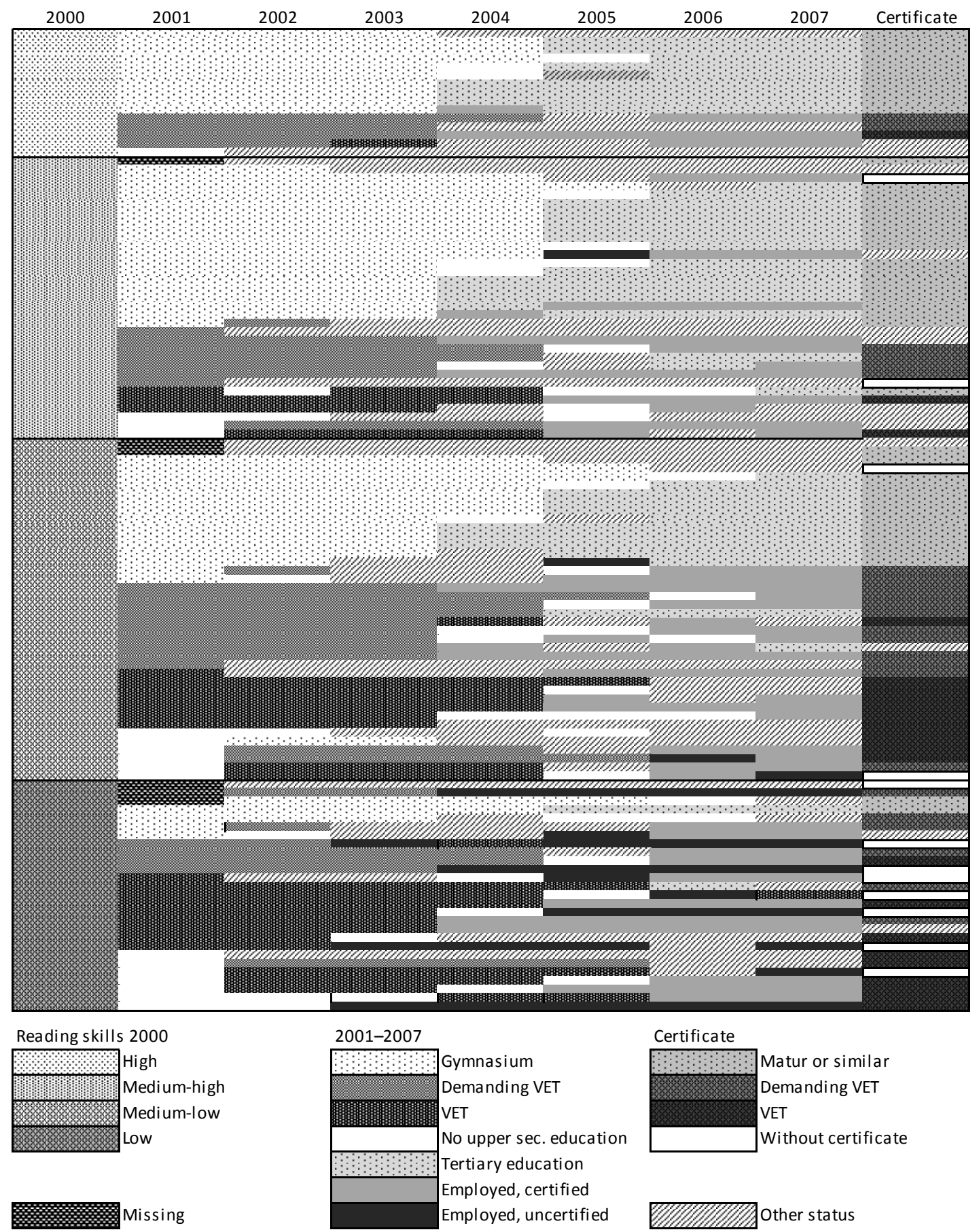

The variety of these patterns is summarized by the entropy index (Figure 2). ${ }^{7}$ In our case, entropy is a measure of the plurality of empirical educational and occupational states at a given point in time. The higher the entropy, the more educational and occupational states are empirically observed (cf. Endnote 6). In Figure 2, we present how entropy develops for two select subgroups of our sample. As a benchmark, we provide the aggregated entropy index for all pathways. 
Figure 2. Entropy of different types of pathways

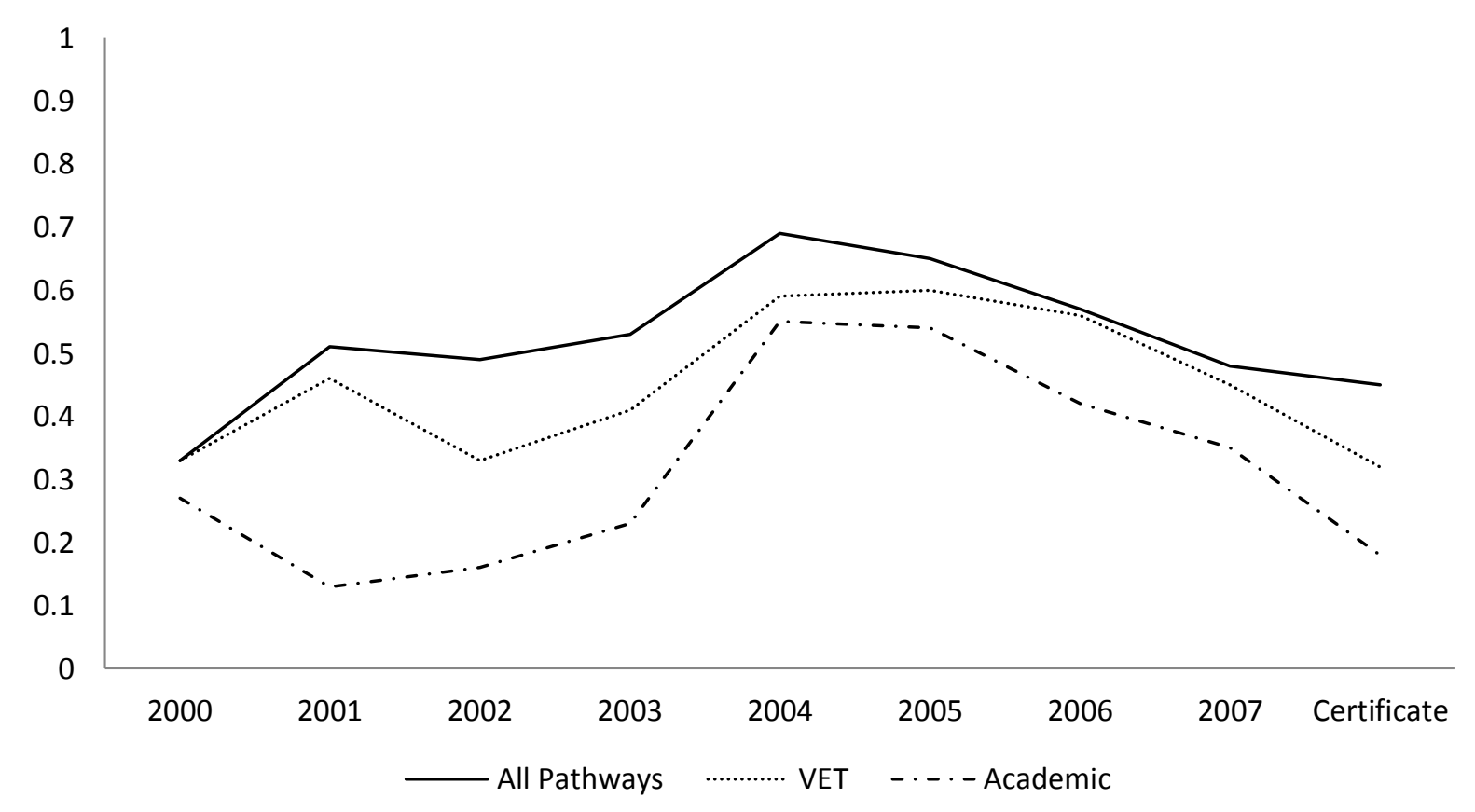

Notes. VET = all persons who entered VET programme within two years after compulsory schooling; Academic = all persons who entered academic track within two years after compulsory schooling.

Entropy is highest for all pathways combined over time (solid line). Interestingly, young people's pathways in VET and academic tracks differ clearly. Those in VET tracks are subject to more entropy than persons in academic tracks. Young people in VET tracks may enter the labour market with occupationspecific credentials as early as two years after compulsory schooling (year 2003 in Figure 2). The most entropy is observed 2004. People in the VET tracks are entering the labour market, further training programmes or becoming unemployed. Most people in the academic track receive their Matur and will have several options as to how to continue their pathways. As times goes on, more similar educational and occupational states are being observed for all types of pathways. This is reflected in a decrease of entropy.
The impact of social background on pathways and persistence tendencies

Persistence tendencies may be depicted as persistence probabilities. They indicate the probability of staying in the same stratum at a subsequent observation period, controlling for the effect of social and personal resources and higher order transition probabilities (i.e. the probability of making a certain transition to a stratum, given all preceding stratum memberships; Figure 3 ). High persistence probabilities show social closure of a given stratum. If the persistence probabilities are high for most or all strata, this indicates that there are few changes between strata. 


\section{Figure 3. Estimated persistence probabilities based on LTA controlling for several covariates}

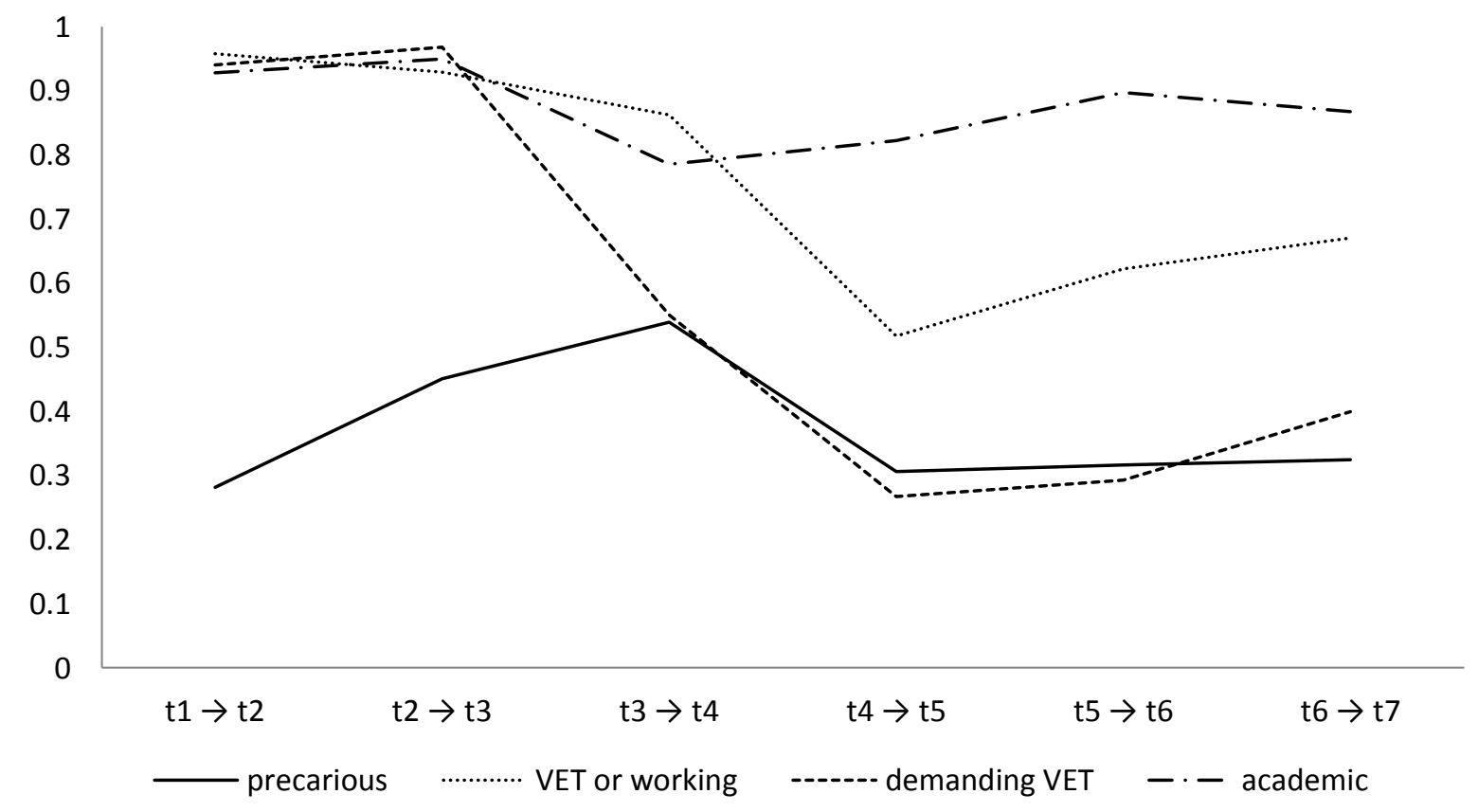

Note. See Appendix 2 for model fit. ${ }^{8}$

The probability of staying in the VET or working, demanding VET and academic strata is high between $t_{1}$ and $t_{3}$. The precarious stratum is markedly different because its members exhibit only a low probability of staying. In the first year after completion of compulsory school, many young people are not in formal upper secondary educational programmes. All strata display decreasing persistence probabilities from $t_{3}$ and $t_{4}$. This is where many young people finish their secondary level II education and are faced with several options. The decrease in the probability of staying in the demanding VET stratum is considerable. Often, these young people obtain a vocational baccalaureate and may enter tertiary education or the labour market, where they encounter spells of not being in education, employment or training (NEET). Members of the academic stratum display different mobilities. On average they are the most likely to stay in their stratum over time. In sum, persistence effects predominate, especially for the academic stratum. These findings corroborate hypothesis 1 . Once in the academic stratum, drop out is unlikely.

Several predictors account for those findings (Table 1). One year after completion of compulsory school, young people from families with little cultural resources and low HISEI are more likely to be in the precarious stratum (odds ratios ${ }^{9}$ are 0.98 and 0.97 , respectively; reference category is high stratum). Similarly, having parents with low levels of education is associated with an elevated likelihood to be in the precarious stratum (2.37). Below average math literacy (1.63) and reading literacy (14.82) have a similar effect. 
The effects of social background on educational and occupational pathways...

Table 1. Odds Ratios based on a Latent Transition Analysis Model

\begin{tabular}{|c|c|c|c|c|c|c|}
\hline \multirow{2}{*}{$\frac{\text { Reference category: academic stratum }}{\text { Cultural resources }}$} & \multicolumn{2}{|c|}{$t_{1}:$ precarious } & \multicolumn{2}{|c|}{$t_{1}$ : VET or working } & \multicolumn{2}{|c|}{$t_{1}$ : demanding VET } \\
\hline & $0.98^{*}$ & $(-2.44)$ & $0.94 * * *$ & $(-8.60)$ & $0.95 * * *$ & $(-6.93)$ \\
\hline HISEI & $0.97^{* * *}$ & $(-8.59)$ & $0.97 * * *$ & $(-9.84)$ & $0.98 * * *$ & $(-7.18)$ \\
\hline Familial economic resources & 1.01 & $(0.21)$ & $1.13 *$ & $(2.21)$ & $1.34^{* * *}$ & $(5.55)$ \\
\hline \multicolumn{7}{|l|}{ Math literacy [above the mark] } \\
\hline at the mark & 1.15 & $(1.34)$ & $0.80^{*}$ & $(-2.23)$ & 1.06 & $(0.57)$ \\
\hline below the mark & $1.63^{* *}$ & (3.19) & 0.97 & $(-0.19)$ & 1.11 & $(0.70)$ \\
\hline \multicolumn{7}{|l|}{ Parents' education [high] } \\
\hline medium & 1.13 & $(1.01)$ & 1.06 & $(0.52)$ & 1.19 & $(1.77)$ \\
\hline low & $2.37 * * *$ & $(6.75)$ & $1.63 * * *$ & (3.93) & $1.40 * *$ & $(2.75)$ \\
\hline \multicolumn{7}{|l|}{ Reading skills [high] } \\
\hline low & $14.82^{* * *}$ & $(13.64)$ & $18.03 * * *$ & $(14.70)$ & $2.39 * * *$ & $(3.83)$ \\
\hline medium-low & $6.15^{* * *}$ & (13.68) & $8.26 * * *$ & $(16.35)$ & $2.25^{* * *}$ & $(6.32)$ \\
\hline \multirow[t]{2}{*}{ medium-high } & $2.64 * * *$ & $(8.73)$ & $3.56 * * *$ & $(11.70)$ & $1.90 * * *$ & $(7.06)$ \\
\hline & \multicolumn{2}{|c|}{$t_{2}:$ precarious } & \multicolumn{2}{|c|}{$t_{2}$ : VET or working } & \multicolumn{2}{|c|}{$t_{2}$ : demanding VET } \\
\hline Cultural resources & $0.96^{*}$ & $(-2.41)$ & $0.94 * * *$ & $(-3.94)$ & $0.94 * * *$ & $(-4.57)$ \\
\hline HISEI & 0.99 & $(-1.46)$ & $0.99 *$ & $(-2.37)$ & 0.99 & $(-1.85)$ \\
\hline Familial economic resources & 0.98 & $(-0.20)$ & 1.20 & $(1.68)$ & $1.31 *$ & $(2.58)$ \\
\hline \multicolumn{7}{|l|}{ Math literacy [above the mark] } \\
\hline at the mark & 0.91 & $(-0.41)$ & 1.13 & $(0.61)$ & 0.84 & $(-0.86)$ \\
\hline below the mark & 1.55 & $(1.44)$ & 1.46 & $(1.26)$ & 1.28 & $(0.83)$ \\
\hline \multicolumn{7}{|l|}{ Parents' education [high] } \\
\hline medium & 1.39 & $(1.34)$ & 0.95 & $(-0.23)$ & 1.04 & $(0.17)$ \\
\hline low & 1.46 & $(1.36)$ & 1.28 & $(0.94)$ & 1.07 & $(0.28)$ \\
\hline \multicolumn{7}{|l|}{ Reading skills [high] } \\
\hline low & $11.60 * * *$ & $(6.94)$ & $13.78^{* * *}$ & $(7.71)$ & $2.57^{* *}$ & $(2.62)$ \\
\hline medium-low & $6.48^{* * *}$ & $(6.54)$ & $6.61 * * *$ & $(7.05)$ & $2.70 * * *$ & $(3.85)$ \\
\hline \multirow[t]{2}{*}{ medium-high } & $1.82^{* *}$ & $(2.61)$ & $2.28^{* * *}$ & $(4.02)$ & 1.43 & $(1.91)$ \\
\hline & \multicolumn{2}{|c|}{$t_{3}:$ precarious } & \multicolumn{2}{|c|}{$t_{3}$ : VET or working } & \multicolumn{2}{|c|}{$t_{3}$ : demanding VET } \\
\hline Cultural resources & 0.99 & $(-0.71)$ & 0.97 & $(-1.77)$ & 0.99 & $(-0.55)$ \\
\hline HISEI & $0.98 * *$ & $(-2.75)$ & $0.98^{* *}$ & $(-2.85)$ & $0.98^{*}$ & $(-2.49)$ \\
\hline Familial economic resources & 0.88 & $(-0.89)$ & 0.91 & $(-0.66)$ & 1.12 & $(0.79)$ \\
\hline \multicolumn{7}{|l|}{ Math literacy [above the mark] } \\
\hline at the mark & $2.16^{* *}$ & $(3.01)$ & 1.47 & $(1.45)$ & 1.20 & $(0.59)$ \\
\hline below the mark & $2.05^{*}$ & $(2.29)$ & 0.90 & $(-0.27)$ & 0.81 & $(-0.55)$ \\
\hline \multicolumn{7}{|l|}{ Parents' education [high] } \\
\hline medium & 1.27 & $(0.90)$ & 1.21 & $(0.67)$ & 1.33 & $(0.90)$ \\
\hline low & 1.52 & $(1.31)$ & 1.20 & $(0.53)$ & 1.74 & $(1.46)$ \\
\hline Reading skills [high] & & & & & & \\
\hline low & $8.42 * * *$ & $(5.25)$ & $3.99 * *$ & $(3.04)$ & 1.15 & $(0.28)$ \\
\hline medium-low & $3.65^{* * *}$ & $(4.21)$ & $2.73^{* *}$ & $(3.30)$ & 1.78 & $(1.64)$ \\
\hline medium-high & $1.88^{*}$ & $(2.37)$ & $2.16^{* *}$ & $(2.89)$ & 1.56 & $(1.56)$ \\
\hline & $t_{4}:$ pre & ous & $t_{4}:$ VET or & rking & $\mathbf{t}_{4}:$ demar & g VET \\
\hline Cultural resources & $0.98^{*}$ & $(-2.25)$ & $0.97^{*}$ & $(-2.53)$ & 0.98 & $(-1.67)$ \\
\hline HISEI & 1.00 & $(-0.76)$ & 1.00 & $(-0.26)$ & 1.00 & $(-0.65)$ \\
\hline Familial economic resource & $0.84^{*}$ & $(-2.29)$ & 0.91 & $(-1.10)$ & 1.02 & $(0.15)$ \\
\hline Math literacy [above the mark] & & & & & & \\
\hline at the mark & 1.25 & $(1.53)$ & 1.20 & $(1.14)$ & 1.16 & $(0.72)$ \\
\hline below the mark & $1.68^{*}$ & $(2.55)$ & 1.36 & $(1.42)$ & 1.45 & $(1.35)$ \\
\hline Parents' education [high] & & & & & & \\
\hline medium & 0.94 & $(-0.41)$ & 0.90 & $(-0.66)$ & 1.19 & $(0.84)$ \\
\hline low & 1.16 & $(0.81)$ & 1.19 & $(0.85)$ & 0.92 & $(-0.32)$ \\
\hline
\end{tabular}


The effects of social background on educational and occupational pathways...

\begin{tabular}{|c|c|c|c|c|c|c|}
\hline \multicolumn{7}{|l|}{ Reading skills [high] } \\
\hline low & 0.98 & $(-0.05)$ & 0.68 & $(-1.08)$ & 0.64 & $(-0.93)$ \\
\hline medium-low & $0.68 *$ & $(-1.97)$ & $0.61^{*}$ & $(-2.34)$ & 0.83 & $(-0.75)$ \\
\hline \multirow[t]{2}{*}{ medium-high } & $0.56^{* * *}$ & $(-3.96)$ & $0.56^{* * *}$ & $(-3.59)$ & $0.62^{*}$ & $(-2.40)$ \\
\hline & \multicolumn{2}{|c|}{$t_{5}:$ precarious } & \multicolumn{2}{|c|}{$t_{5}:$ VET or working } & \multicolumn{2}{|c|}{$t_{5}$ : demanding VET } \\
\hline Cultural resource & 0.99 & $(-1.22)$ & 1.00 & $(-0.60)$ & 1.01 & $(0.62)$ \\
\hline HISEI & 1.00 & $(-0.21)$ & 1.00 & $(-1.39)$ & 1.01 & $(0.88)$ \\
\hline Familial economic resources & 0.93 & $(-1.21)$ & $0.85^{* *}$ & $(-3.27)$ & 0.83 & $(-1.56)$ \\
\hline \multicolumn{7}{|l|}{ Math literacy [above the mark] } \\
\hline at the mark & 1.16 & $(1.40)$ & 1.12 & $(1.26)$ & $1.94^{* *}$ & $(3.04)$ \\
\hline below the mark & 1.30 & $(1.85)$ & 1.00 & $(0.01)$ & $1.82^{*}$ & $(2.07)$ \\
\hline \multicolumn{7}{|l|}{ Parents' education [high] } \\
\hline medium & 1.02 & $(0.16)$ & $1.22 *$ & $(1.97)$ & 1.44 & $(1.39)$ \\
\hline low & 0.84 & $(-1.39)$ & 1.00 & $(-0.03)$ & 1.04 & $(0.12)$ \\
\hline \multicolumn{7}{|l|}{ Reading skills [high] } \\
\hline low & 0.85 & $(-0.93)$ & $0.75^{*}$ & $(-2.02)$ & 1.21 & $(0.41)$ \\
\hline medium-low & 1.13 & $(0.89)$ & 0.92 & $(-0.73)$ & 1.55 & $(1.58)$ \\
\hline \multirow[t]{2}{*}{ medium-high } & 1.06 & $(0.50)$ & 0.98 & $(-0.22)$ & 1.26 & $(0.94)$ \\
\hline & \multicolumn{2}{|c|}{$t_{6}:$ precarious } & \multicolumn{2}{|c|}{$t_{6}:$ VET or working } & \multicolumn{2}{|c|}{$t_{6}:$ demanding VET } \\
\hline Cultural resources & 1.01 & $(1.05)$ & 1.01 & $(1.25)$ & 1.01 & $(0.38)$ \\
\hline HISEI & 0.99 & $(-1.41)$ & $0.99 * *$ & $(-2.68)$ & 1.01 & $(0.47)$ \\
\hline Familial economic resources & 1.01 & $(0.14)$ & 0.96 & $(-0.76)$ & 0.93 & $(-0.38)$ \\
\hline \multicolumn{7}{|l|}{ Math literacy [above the mark] } \\
\hline at the mark & 1.26 & $(1.82)$ & 1.19 & $(1.61)$ & 1.54 & $(1.46)$ \\
\hline below the mark & 1.38 & $(1.90)$ & 1.14 & $(0.86)$ & 0.81 & $(-0.44)$ \\
\hline \multicolumn{7}{|l|}{ Parents' education [high] } \\
\hline medium & 1.29 & $(1.82)$ & $1.36^{*}$ & $(2.51)$ & 1.86 & $(1.67)$ \\
\hline low & 1.03 & $(0.15)$ & 1.18 & $(1.29)$ & 1.68 & $(1.22)$ \\
\hline \multicolumn{7}{|l|}{ Reading skills [high] } \\
\hline low & 0.97 & $(-0.13)$ & 1.14 & $(0.78)$ & 1.18 & $(0.32)$ \\
\hline medium-low & $1.39 *$ & $(2.04)$ & $1.37^{*}$ & $(2.31)$ & 1.70 & $(1.44)$ \\
\hline \multirow[t]{2}{*}{ medium-high } & 1.24 & $(1.61)$ & 1.23 & $(1.83)$ & 0.98 & $(-0.06)$ \\
\hline & \multicolumn{2}{|c|}{$t_{7}:$ precarious } & \multicolumn{2}{|c|}{$t_{7}:$ VET or working } & \multicolumn{2}{|c|}{$t_{7}$ : demanding VET } \\
\hline Cultural resources & 1.00 & $(-0.30)$ & 0.98 & $(-1.90)$ & 0.95 & $(-1.48)$ \\
\hline HISEI & 1.00 & $(-0.42)$ & $0.99 *$ & $(-2.14)$ & 1.00 & $(0.30)$ \\
\hline Familial economic resources & 0.99 & $(-0.19)$ & 0.99 & $(-0.09)$ & 0.76 & $(-1.19)$ \\
\hline \multicolumn{7}{|l|}{ Math literacy [above the mark] } \\
\hline at the mark & $1.47^{* *}$ & $(2.81)$ & 1.03 & $(0.25)$ & 0.90 & $(-0.22)$ \\
\hline below the mark & 1.17 & $(0.75)$ & 0.98 & $(-0.15)$ & 1.14 & $(0.19)$ \\
\hline \multicolumn{7}{|l|}{ Parents' education [high] } \\
\hline medium & 0.97 & $(-0.18)$ & 0.98 & $(-0.20)$ & 0.59 & $(-1.09)$ \\
\hline low & 1.11 & $(0.57)$ & 1.09 & $(0.62)$ & 0.25 & $(-1.89)$ \\
\hline \multicolumn{7}{|l|}{ Reading skills [high] } \\
\hline low & 1.29 & $(1.02)$ & 0.90 & $(-0.60)$ & 0.43 & $(-0.87)$ \\
\hline medium-low & 1.18 & $(0.90)$ & 0.81 & $(-1.59)$ & 0.43 & $(-1.50)$ \\
\hline medium-high & 1.23 & $(1.31)$ & 0.92 & $(-0.72)$ & 1.37 & $(0.67)$ \\
\hline
\end{tabular}

Notes. T-values in brackets; ${ }^{*} p<0.050 ;{ }^{* *} p<0.010 ;{ }^{* *} p<0.001 . n=5117$; comparison to model without covariates: $\Delta$ LogLikelihood $=4669$ with $\Delta d f=210$ (adjusted $\Delta B I C=8241$ ). Coefficients for autoregressive effects are not displayed. 
The effects of social background on educational and occupational pathways...

In the second year after completion of compulsory school, only objectified cultural resources and reading skills are significant. Effects of enrolment have an effect in the form of persistence probabilities after two years (odds ratios not shown in Table 1; see Figure 2 for a visualisation).

The odds ratios corroborate hypothesis 2 but should not be compared (Allison, 1999; Mood, 2010). As an alternative, we propose to observe the diminishing effect of social background on pathways via the number of significant predictors measuring social background. The effect of social background decreases over time from 3 significant predictors at $t_{1}$ to 0 significant predictors at $t_{7}$ (cf. Table 1: $\mathrm{t}_{1}=3, \mathrm{t}_{2}=2, \mathrm{t}_{3}=1, \mathrm{t}_{4}=2, \mathrm{t}_{5}=0, \mathrm{t}_{6}=0, \mathrm{t}_{7}=$ $0)$. This pattern is repeated for the other strata and further supports hypothesis 2 .

Cultural resources, parents' socio-economic status and education are crucial for the transition from compulsory school to secondary level II. During secondary level II, only cultural resources and parents' socio-economic status seem to matter. For the transition from secondary level II to the labour market, economic resources also play a role. Wealth decreases the risk of being in the precarious stratum (e.g. NEET).

\section{Discussion and conclusion}

In this paper, we analyse educational and occupational pathways of young people in an education system characterised by elements that have been shown in other studies to both reinforce and weaken social background effects. Using Switzerland as a case study, we draw on Elder's work and conceptualized positions within pathways as strata (Elder, 1975, 1994).

We examine how different strata are linked over time and consider institutional opportunity structures and personal action windows. In a first step, we describe pathways in association with competencies for a period of seven years following compulsory school. Subsequently, we analyse the effect of social background on pathways at different times.

The first set of results reveals increasing variations of educational pathways over time. The highest variance of educational and occupational positions is observed after four years. This finding is most likely due to the many ways of how young people use institutional opportunity structures. For example, some enter a VET programme with some delay, while others follow institutional and societal expectations. The variety of pathways following VET is larger than those following the academic track. This bumpiness in the pathways is mostly due to NEET spells, but also mobility between strata. As proposed in other research (Hupka-Brunner, Samuel, Huber, \& Bergman, 2011), delayed entry into the labour market or other non-normative educational and occupational pathways might be stigmatising.

The second set of results supports our hypothesis that persistence tendencies are more pronounced in the academic stratum, compared to the lower strata. Young people with high reading skills are most likely to transform their skills into apposite educational and occupational pathways. The precarious stratum does not seem to be a dead end, at least not for the majority of its incumbents. Also, the findings show a direct effect of social background. This is especially the case at early stages of educational and occupational pathways. Controlling for indirect effects of social background, there are negligible direct effects seven years after completion of compulsory school. Furthermore, different resources seem to affect pathways in particular ways. Cultural and economic resources matter at the beginning of post-compulsory schooling. During the secondary level II, only cultural resources and parents' socio-economic status had an effect. For the transition from secondary level II to the labour market, economic resources also play a role. Wealth decreases the risk of being in the precarious stratum (e.g. NEET). These findings show that a detailed analysis of social background allows for a better and more time-sensitive understanding of social reproduction. Our findings indicate that there are two processes at play. Social background and performance determine selection into tracks. Then persistence tendencies, as observable effects of opportunity structures, take over. Moreover, the cost of the transfer of inter-generational advantage in such education systems, is somewhat offset by the ability to integrate fairly weak academic performers into the labour market via the multiplicity of educational pathways and a strongly structured vocational training.

On a theoretical level, the life course perspective and the broad conceptualisation of social background proves fruitful. This supports a focus on different contexts and how they reward different 
The effects of social background on educational and occupational pathways...

resources and how this process contributes to the accumulation or compensation of disadvantages. The Swiss system, as a representative of education systems with VET programmes, offers young people the possibility to attend tertiary education even after an apprenticeship, given a federal vocational baccalaureate. This opportunity seems to depend less on parental backgrounds and more on skills. If skilled, young people from disadvantaged backgrounds seem to be given a second chance. On the other hand, elevated economic resources appear to inoculate against low stratum membership for all observational periods.

As a methodological contribution, we suggest a two-step approach. First, we provide a thorough description of pathways using sequence analysis and optimal matching. The entropy index proves to be especially helpful in our study. Second, an analytical examination of pathways using LTA follows. This approach seems to have advantages over, for example, fixed effects estimation, which typically provides time-averaged estimates. We believe that particularly the study of noisy patterns, which are abundant in life course studies, might benefit from an approach along the lines we are proposing.

Our findings have practical implications. The comparably high permeability of the lower strata is striking and desirable from an educational policy perspective. However, this does not hold for the academic stratum, which is relatively impervious and especially prone to social background influences. This is even more noteworthy in educational contexts, where tertiary education participation is low. Overall, we have shown that a strong and early tracking offers many opportunities for social integration and upward mobility, even though social background and tracking are still the most important factors in explaining young people's educational and occupational pathways.

\section{Acknowledgement}

This research was partially financed by the Swiss National Science Foundation grant PBBSP1_141399.

\section{References}

Abbott, A., \& Tsay, A. (2000). Sequence Analysis and Optimal Matching Methods in Sociology: Review and Prospect. Sociological Methods Research, 29, 3-33. http://dx.doi.org/10.1177/0049124100029001001

Adams, R., \& Wu, M. (Eds.). (2002). PISA 2000 Technical Report. Paris: OECD/PISA.

Allison, P. D. (1999). Comparing Logit and Probit Coefficients Across Groups. Sociological Methods \& Research, 28, 186-208. http://dx.doi.org/10.1177/0049124199028002003

Andersen, P. L., \& Hansen, M. N. (2012). Class and Cultural Capital-The Case of Class Inequality in Educational Performance. European Sociological Review, 28, 607-621. http://dx.doi.org/10.1093/esr/jcr029

Baltes, P. B. (1987). Theoretical propositions of life-span developmental psychology: On the dynamics between growth and decline. Developmental Psychology, 23, 611-626. http://dx.doi.org/10.1037/0012-1649.23.5.611

Bauer, P., \& Riphahn, R. T. (2006). Timing of school tracking as a determinant of intergenerational transmission of education. Economic Letters, 91, 90-97. http://dx.doi.org/10.1016/i.econlet.2005.11.003

Becker, R. (2010). Soziale Ungleichheit im Schweizer Bildungssystem und was man dagegen tun könnte. In M. P. Neuenschwander \& H.-U. Grunder (Eds.), Schulübergang und Selektion Forschungsbefunde, Praxisbeispiele, Umsetzungsperspektiven (pp. 91-108). Chur: Rüegger.

Becker, R., \& Hecken, A. E. (2009a). Higher Education or Vocational Training? An Empirical Test of the Rational Action Model of Educational Choices Suggested by Breen and Goldthorpe and Esser. Acta Sociologica, 52, 25-45. http://dx.doi.org/10.1177/0001699308100632

Becker, R., \& Hecken, A. E. (2009b). Why are Working-class Children Diverted from Universities? An Empirical Assessment of the Diversion Thesis. European Sociological Review, 25, 233-250.

Berger, P. A., \& Kahlert, H. (Eds.). (2005). Institutionalisierte Ungleichheiten. Wie das Bildungswesen Chancen blockiert. Weinheim und München: Juventa.

BFS (Ed.). (2007a). Bildungsmosaik Schweiz. Bildungsindikatoren 2007. Neuchâtel: Bundesamt für Statistik. BFS (Ed.). (2007b). Maturitäten und Übertritte an Hochschulen 2006. Neuchâtel: Bundesamt für Statistik.

Blossfeld, H.-P., \& Maurice, J. von. (2011). Education as a lifelong process. Zeitschrift für Erziehungswissenschaft, 14, 19-34. http://dx.doi.org/10.1007/s11618-011-0179-2

Blossfeld, H.-P., \& Shavit, Y. (1993). Persisting Barriers. Changes in Educational Opportunities in Thirteen Countries. In Y. Shavit \& H.-P. Blossfeld (Eds.), Persistent Inequality: Changing Educational Attainment in Thirteen Countries. San Francisco: Westview Press. 
The effects of social background on educational and occupational pathways...

Bourdieu, P. (2000). Reproduction in Education, Society and Culture (2. ed., repr.). London: Sage Publications.

Bowlby, J. W., \& McMullen, K. (2002). At a Crossroads: First Results for the 18 to 20-Year-old Cohort of the Youth in Transition Survey. Human Resources and Skills Development Canada, Ottawa. Website: http://www.hrsdc.gc.ca/eng/home.shtml

Brzinsky-Fay, C., Kohler, U., \& Luniak, M. (2006). Sequence Analysis with Stata. Stata Journal, 6, 435-460.

Buchholz, S., Imdorf, C., Hupka-Brunner, S., \& Blossfeld, H.-P. (2012). Sind leistungsschwache Jugendliche tatsächlich nicht ausbildungsfähig? Kölner Zeitschrift für Soziologie und Sozialpsychologie, 64, 701727. http://dx.doi.org/10.1007/s11577-012-0186-1

Bukodi, E., \& Goldthorpe, J. H. (2013). Decomposing "Social Origins": The Effects of Parents' Class, Status, and Education on the Educational Attainment of Their Children. European Sociological Review, 29, 1024-1039. http://dx.doi.org/10.1093/esr/jcs079

Chung, H., Park, Y., \& Lanza, S. T. (2005). Latent transition analysis with covariates: pubertal timing and substance use behaviours in adolescent females. Statistics in Medicine, 24, 2895-2910. http://dx.doi.org/10.1002/sim.2148

Coradi Vellacott, M., Hollenweger, J., Nicolet, M., \& Wolter, S. C. (2003). Soziale Integration und Leistungsförderung. Thematischer Bericht der Erhebung PISA 2000. Neuchâtel: BFS/EDK.

DiPrete, T., \& Eirich, G. (2006). Cumulative advantage as a mechanism for inequality: A review of theoretical and empirical developments. Annual Review of Sociology, 32, 271-297. http://dx.doi.org/10.1146/annurev.soc.32.061604.123127

Elder, G. H. (1975). Age Differentiation and the Life Course. Annual Review of Sociology, 1, 165-190. http://dx.doi.org/10.1146/annurev.so.01.080175.001121

Elder, G. H. (1994). Time, Human Agency, and Social Change: Perspectives on the Life Course. Social Psychology Quarterly, 57, 4. http://dx.doi.org/10.2307/2786971

Erikson, R., \& Goldthorpe, J. H. (1992). The Constant Flux: A Study of Class Mobility in Industrial Societies. Oxford: Clarendon Press.

Erikson, R., \& Jonsson, J. O. (1996). Explaining Class Inequality in Education: The Swedish Test Case. In R. Erikson \& J. O. Jonsson (Eds.), Can Education Be Equalized? (pp. 1-63). Boulder: Westview Press.

Finnie, R., \& Mueller, R. E. (2009). The backgrounds of Canadian youth and access to post-secondary education: New evidence from the Youth in Transition Survey. In R. Finnie et al. (Eds.) Who Goes, Who Stays, What Matters: Access to and Remaining in Post-Secondary Education in Canada (pp. 78-108). Montreal-Kingston: McGill-Queen's University Press.

Gabadinho, A., Ritschard, G., Studer, M., \& Müller, N. S. (2010). Mining Sequence Data in R with the Traminer Package: A User's Guide. University of Geneva. Retrieved from: http://mephisto.unige.ch/traminer

Gangl, M. (2001). European Patterns of Labour Market Entry. A dichotomy of occupationalized vs. nonoccupationalized systems? European Societies, 3, 471-494. http://dx.doi.org/10.1080/14616690120112226

Goldthorpe, J. H. (1996). Class analysis and the reorientation of class theory: the case of persisting differentials in educational attainment. British Journal of Sociology, 47, 481-505. http://dx.doi.org/10.2307/591365

Goldthorpe, J. H., Llewellyn, C., \& Payne, C. (1987). Social mobility and class structure in modern Britain. Oxford: Clarendon Press .

Goodman, A., Gisselmann, M. D., \& Koupil, I. (2010). Birth outcomes and early-life social characteristics predict unequal educational outcomes across the life course and across generations. Longitudinal and Life Course Studies, 1, 317-338.

Gregg, P., \& Macmillan, L. (2010). Family income, education and cognitive ability in the next generation: exploring income gradients in education and test scores for current cohorts of youth. Longitudinal and Life Course Studies, 1, 259-280.

Heinz, W. R., Weymann, A., \& Huinik, J. (Eds.). (2009). The Life Course Reader. Individuals and Societies Across Time. Frankfurt am Main: Campus.

Homel, J., Mavisakalyan, A., Nguyen, H. T., \& Ryan, C. (2012). School Completion: What We Learn from Different Measures of Family Background. Longitudinal Surveys of Australian Youth. Research Report 59. National Centre for Vocational Education Research, Adelaide. Website: http://www.ncver.edu.au

Humphreys, K., \& Janson, H. (2000). Latent Transition Analysis with Covariates, Nonresponse, Summary Statistics and Diagnostics: Modelling Children's Drawing Development. Multivariate Behavioral Research, 35, 89-118. http://dx.doi.org/10.1207/S15327906MBR3501 4

Hupka-Brunner, S., Sacchi, S., \& Stalder, B. E. (2010). Social Origin and Access to Upper Secondary Education in Switzerland: A Comparison of Company-based Apprenticeship and Exclusively School-based Programmes. Schweizerische Zeitschrift für Soziologie, 36, 5-35.

Hupka-Brunner, S., Samuel, R., Huber, E., \& Bergman, M. M. (2011). Geschlechterungleichheiten im intergenerationalen Bildungstransfer in der Schweiz. In A. Hadjar (Ed.), Geschlechtsspezifische 
The effects of social background on educational and occupational pathways...

Bildungsungleichheiten (pp. 77-98). Wiesbaden: VS Verlag für Sozialwissenschaften. http://dx.doi.org/10.1007/978-3-531-92779-4 4

International Labour Office (ILO).(2011). ILOSTAT Database. Geneva: ILO.

Jackson, M. (2013). Determined to Succeed? Performance versus Choice in Educational Attainment. Palo Alto: Stanford University Press. http://dx.doi.org/10.11126/stanford/9780804783026.001.0001

Jackson, M., Jonsson, J. O., \& Rudolphi, F. (2012). Ethnic Inequality in Choice-driven Education Systems. A Longitudinal Study of Performance and Choice in England and Sweden. Sociology of Education, 85, 158-178. http://dx.doi.org/10.1177/0038040711427311

Joye, D., Bergman, M. M., \& Lambert, P. S. (2003). Intergenerational Educational and Social Mobility in Switzerland. Schweizerische Zeitschrift für Soziologie, 29, 263-291.

Jungbauer-Gans, M. (2004). Einfluss des sozialen und kulturellen Kapitals auf die Lesekompetenz. Ein Vergleich der PISA-Daten aus Deutschland, Frankreich und der Schweiz. Zeitschrift für Soziologie, 5, 375-397.

Kohli, M. (2007). The Institutionalization of the Life Course: Looking Back to Look Ahead. Research in Human Development, 4, 253-271. http://dx.doi.org/10.1080/15427600701663122

Konietzka, D. (2010). Zeiten des Übergangs: Sozialer Wandel des Übergangs in das Erwachsenenalter. Wiesbaden: VS Verlag für Sozialwissenschaften. http://dx.doi.org/10.1007/978-3-531-92229-4

Kronig, W. (2007). Die systematische Zufälligkeit des Bildungserfolgs. Theoretische Erklärungen und empirische Untersuchungen zur Lernentwicklung und zur Leistungsbewertung in unterschiedlichen Schulklassen. Bern: Haupt.

Lazarsfeld, P. F. (1968). Latent Structure Analysis. Boston: Houghton Mifflin Company.

Levy, R., Ghisletta, P., Goff, J.-M. L., Spini, D., \& Widmer, E. (2005). Towards an Interdisciplinary Perspective on the Life Course. Amsterdam: Elsevier.

Lin, J. Y., Ten Have, T. R., \& Elliott, M. R. (2009). Nested Markov Compliance Class Model in the Presence of Time-Varying Noncompliance. Biometrics, 65, 505-513. http://dx.doi.org/10.1111/j.1541-0420.2008.01113.x

Maaz, K., Watermann, R., \& Baumert, J. (2007). Family background, competence development, and selective decisions within the tiered school system compared internationally - An extensive analysis of PISA data. Zeitschrift für Padagogik, 53, 444-461.

Mare, R. D. (1980). Social Background and School Continuation Decisions. Journal of the American Statistical Association, 75, 295-305. http://dx.doi.org/10.1080/01621459.1980.10477466

Mclntosh, S. (2006). Further Analysis of the Returns to Academic and Vocational Qualifications. Oxford Bulletin of Economics and Statistics, 68, 225-251. http://dx.doi.org/10.1111/i.1468-0084.2006.00160.x

Merton, R. K. (1968). Social Theory and Social Structure (1968 enlarged ed.). New York: The Free Press.

Miglioretti, D. L. (2003). Latent Transition Regression for Mixed Outcomes. Biometrics, 59, 710-720. http://dx.doi.org/10.1111/1541-0420.00082

Mood, C. (2010). Logistic Regression: Why We Cannot Do What We Think We Can Do, and What We Can Do About It. European Sociological Review, 26, 67 -82. http://dx.doi.org/10.1093/esr/jcp006

Moser, U. (2004). Jugendliche zwischen Schule und Berufsbildung. Eine Evaluation bei Schweizer Grossunternehmen unter Berücksichtigung des internationalen Schulleistungsvergleichs PISA. Bern: h.e.p. Verlag.

Muthen, B., \& Muthen, L. K. (2000). Integrating person-centered and variable-centered analyses: Growth mixture modeling with latent trajectory classes. Alcoholism-Clinical and Experimental Research, 24, 882-891. http://dx.doi.org/10.1111/j.1530-0277.2000.tb02070.x

Neuenschwander, M. P., Gerber, M., Frank, N., \& Rottermann, B. (Eds.). (2012). Schule und Beruf - Wege in die Erwerbstätigkeit. Wiesbaden: VS Verlag für Sozialwissenschaften. http://dx.doi.org/10.1007/978-3-531-94156-1

Neuenschwander, M. P., \& Malti, T. (2009). Selektionsprozesse beim Übergang in die Sekundarstufe I und II. Zeitschrift für Erziehungswissenschaft, 12, 216-232. http://dx.doi.org/10.1007/s11618-2009-0074-2

Nylund, K. L. (2007). Latent Transition Analysis. Los Angeles: University of California.

OECD/PISA (Ed.). (2001). Knowledge and Skills for Life. First Results from PISA 2000. Paris.

Raykov, T. (2005). Analysis of Longitudinal Studies With Missing Data Using Covariance Structure Modeling With Full-Information Maximum Likelihood. Structural Equation Modeling, 12, 493. http://dx.doi.org/10.1207/s15328007sem1203 8

Reboussin, B. A., \& Ialongo, N. S. (2010). Latent transition models with latent class predictors: attention deficit hyperactivity disorder subtypes and high school marijuana use. Journal of the Royal Statistical Society Series A (Statistics in Society), 173, 145-164. http://dx.doi.org/10.1111/j.1467-985X.2009.00607.x

Renaud, A., Ramseier, E., \& Zahner, C. (2000). PISA 2000: Sampling in Switzerland. General Information and Design. Paris: PISA Consortium. 
Sacchi, S. (2011). Construction of TREE Panel Weights. Documentation for the Panel Waves from 2000 to 2010. Basel, Zürich: TREE \& cue sozialforschung.

Schindler, S., \& Lörz, M. (2012). Mechanisms of Social Inequality Development: Primary and Secondary Effects in the Transition to Tertiary Education Between 1976 and 2005. European Sociological Review, 28, 647-660. http://dx.doi.org/10.1093/esr/jcr032

Schoon, I., \& Silbereisen, R. K. (2009). Transitions from school to work: Globalization, individualization, and patterns of diversity. Cambridge: Cambridge University Press. http://dx.doi.org/10.1017/CBO9780511605369

SKBF (Ed.). (2010). Bildungsbericht Schweiz 2010. Aarau: Schweizerische Koordinationsstelle für Bildungsforschung.

Stalder, B. E. (2005). Das intellektuelle Anforderungsniveau von 105 Berufslehren (Internes Arbeitspapier). TREE.

Stalder, B. E., Meyer, T., \& Hupka, S. (2008). Leistungsschwach - Bildungsarm? PISA-Kompetenzen als Prädiktoren für nachobligatorische Bildungschancen. Die Deutsche Schule, 100, 436-448.

TREE (Ed.). (2011). Project Documentation 2000-2010. Basel: TREE.

Wiggins, L. M. (1973). Panel Analysis Latent Probalility Models for Attitude and Behavior Processes. San Francisco: Jossey-Bass.

Zutavern, M., Brühwiler, C., \& Biedermann, H. (2002). Die Leistungen der verschiedenen Schultypen auf der Sekundarstufe I. In BFS/EDK (Ed.), Bern, St. Gallen, Zürich: Für das Leben gerüstet? Die Grundkompetenzen der Jugendlichen - Kantonaler Bericht der Erhebung PISA 2000. Neuchâtel.

\section{Appendix}

\section{Appendix 1a. Cross-sectional proportions in percent}

\begin{tabular}{|c|c|c|c|c|c|c|c|c|}
\hline Wave & $t_{0}$ & $t_{1}$ & $t_{2}$ & $t_{3}$ & $t_{4}$ & $t_{5}$ & $t_{6}$ & $t_{7}$ \\
\hline \multicolumn{9}{|l|}{ Strata in Figure 1} \\
\hline \multicolumn{9}{|l|}{ Reading skills PISA 2000} \\
\hline High & 10.61 & & & & & & & \\
\hline Medium-high & 30.04 & & & & & & & \\
\hline Medium-low & 34.68 & & & & & & & \\
\hline Low & 24.66 & & & & & & & \\
\hline \multicolumn{9}{|l|}{ Strata2001-2007 in Figure 1} \\
\hline Gymnasium & & 42.50 & 41.79 & 39.92 & 24.06 & 6.91 & 1.95 & 0.58 \\
\hline Demanding VET & & 19.45 & 23.40 & 24.03 & 14.60 & 5.49 & 2.40 & 1.62 \\
\hline VET & & 18.47 & 23.86 & 23.80 & 20.36 & 11.18 & 6.53 & 4.43 \\
\hline No upper secondary education & & 14.85 & 5.11 & 2.45 & 11.38 & 14.75 & 12.40 & 11.28 \\
\hline Tertiary education & & & & 1.14 & 9.89 & 29.57 & 40.48 & 44.19 \\
\hline Employed, certified & & & & 0.76 & 12.95 & 25.20 & 27.17 & 35.09 \\
\hline Employed, uncertified & & & & 1.59 & 2.20 & 2.35 & 1.95 & 2.33 \\
\hline Missing & & 4.73 & 5.84 & 6.30 & 4.55 & 4.55 & 7.13 & 0.48 \\
\hline
\end{tabular}

Certificate 2007

Matur or similar

41.16

Demanding VET

VET

Without certificate

Strata in Figure 2 and Table 1

Precarious

$\begin{array}{lllllll}18.46 & 6.49 & 5.36 & 14.80 & 15.23 & 11.86 & 9.65\end{array}$

VET or working

Demanding VET

22.59

29.04

28.35

36.17

29.79

27.48

29.71

Academic

19.66

25.05

26.30

15.51

4.49

1.75

1.09

$\begin{array}{lllllll}39.29 & 39.42 & 39.99 & 33.52 & 50.49 & 58.91 & 59.55\end{array}$ 
Appendix 1b. Cross-sectional proportions in percent and mean and standard deviations (SD) for continuous variables

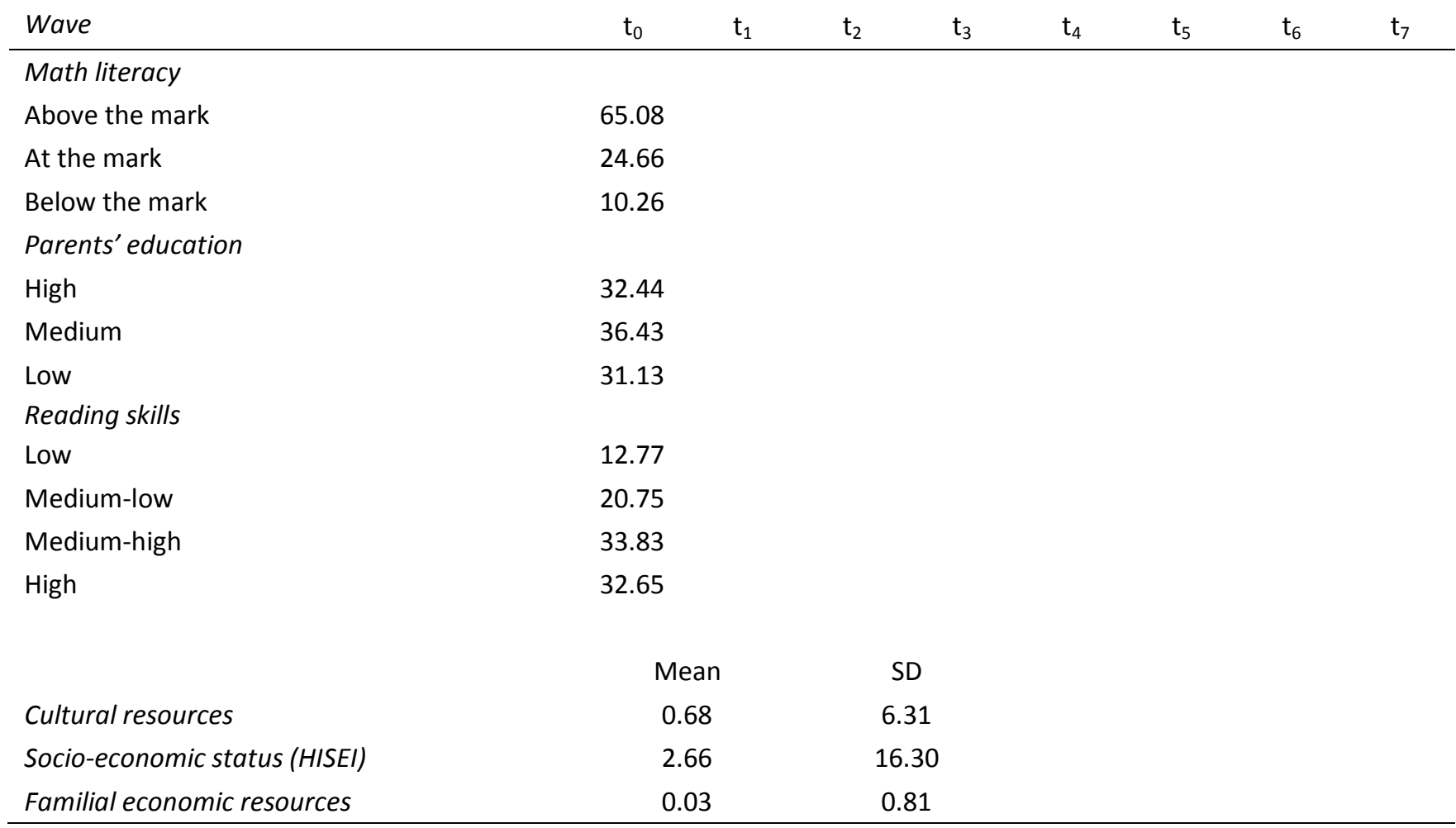

\section{Appendix 2. Log Likelihood (LogL), AIC, BIC and sample size adjusted BIC (BIC adj.) for the} different models.

\begin{tabular}{|c|c|c|c|c|c|c|}
\hline Covariates & $\log L$ & $A I C$ & $B I C$ & BIC adj. & $N$ & $\begin{array}{c}\text { No. of } \\
\text { parameters }\end{array}$ \\
\hline None & -27035.62 & 54491.23 & 55892.92 & 55225.60 & 5853 & 210 \\
\hline Cultural resources & -26295.14 & 53052.28 & 54590.68 & 53856.63 & 5766 & 231 \\
\hline $\begin{array}{l}\text { Cultural resources, socio- } \\
\text { economic status (HISEI) }\end{array}$ & -24026.44 & 48556.88 & 50215.61 & 49414.83 & 5336 & 252 \\
\hline $\begin{array}{l}\text { Cultural resources, socio- } \\
\text { economic status (HISEI), } \\
\text { familial economic resources }\end{array}$ & -23981.10 & 48508.20 & 50305.10 & 49437.59 & 5335 & 273 \\
\hline $\begin{array}{l}\text { Cultural resources, socio- } \\
\text { economic status (HISEI), } \\
\text { familial economic resources, } \\
\text { math literacy }\end{array}$ & -23923.64 & 48477.28 & 50550.62 & 49549.66 & 5335 & 315 \\
\hline $\begin{array}{l}\text { Cultural resources, socio- } \\
\text { economic status (HISEI), }\end{array}$ & & & & & & \\
\hline $\begin{array}{l}\text { familial economic resources, } \\
\text { math literacy, parents' } \\
\text { education }\end{array}$ & -22824.89 & 46363.78 & 48698.95 & 47564.53 & 5121 & 357 \\
\hline $\begin{array}{l}\text { Cultural resources, socio- } \\
\text { economic status (HISEI), } \\
\text { familial economic resources, } \\
\text { math literacy, parents' } \\
\text { education, reading skills }\end{array}$ & -22366.02 & 45572.03 & 48318.97 & 46984.35 & 5117 & 420 \\
\hline
\end{tabular}




\section{Endnotes}

${ }^{1}$ A Gymnasium is a preparatory school for university in Austria, Germany, Switzerland and other countries. The certificate obtained is called Matura (Austria), Abitur (Germany) or Matur(a) (Switzerland).

${ }^{2}$ The most important reason for low persistence tendencies in the vocational track is the permeable structure of tracks on this education level. In other words, people should be able to move easily between the lower tracks. For example, people in the vocational tracks are often affected by gaps and delays.

${ }^{3}$ The indicator "wealth" comprises self-reported information on whether a family has a dishwasher at home and the young person has a room of his or her own, educational software and internet access. Furthermore, the number of mobile phones, televisions, computers, cars and bathrooms is factored into that composite measure. We judge this to be an acceptable proxy for familial economic resources because the information was retrieved from 15-year olds who are usually not well-informed about their parents' assets and accounts. The correlation with other measures of social background is low $(.18<r<.25)$. Collinearity statistics do not point to any problems of using family economic resources in the same model with the other measures of social background (VIF = 1.09).

${ }^{4}$ PISA reading levels 0 and $1=$ low, $2=$ medium-low, $3=$ medium-high, 4 and $5=$ high.

${ }^{5}$ A stepwise approach was developed to generate starting values for first and higher-order transition probabilities between strata, because these models are computationally demanding.

${ }^{6}$ Changes within a stratum and between episodes are not observed. This may hint at short interruptions of education programmes during secondary level II. Most major interruptions in pathways seem to occur at the general thresholds in the education system ( $1^{\text {st }}$ and $2^{\text {nd }}$ threshold; Schmid, 2009).

${ }^{7}$ We used Gabadinho and colleagues' (2010) TraMiner Package in R and applied the Shannon entropy: $h\left(p_{1}, \ldots, p_{s}\right)=-\sum_{i=1}^{s} p_{i} \log \left(p_{i}\right)$, where $p_{i}$ is the proportion of cases in state $i$ at the time point of interest, and $s$ is the number of possible states (Gabadinho et al., 2010:67).

${ }^{8}$ The graph in Figure 3 suggests a drop in the absolute level of persistence probabilities between $t_{3}$ and $t_{5}$. This reflects changes in the marginal distributions during this period. People change strata a lot during this time. Note that changes in the marginal distribution do not tell us much about the patterns of movement between strata. We also argue that the growth of the academic stratum over the last three time points does not reflect or explain persistence.

${ }^{9}$ Odds ratio is a measure of association between a condition and an outcome. It refers to the odds that an outcome will occur, given a particular condition, compared to the odds of an outcome, if the condition does not occur. It is a ratio of two odds. 